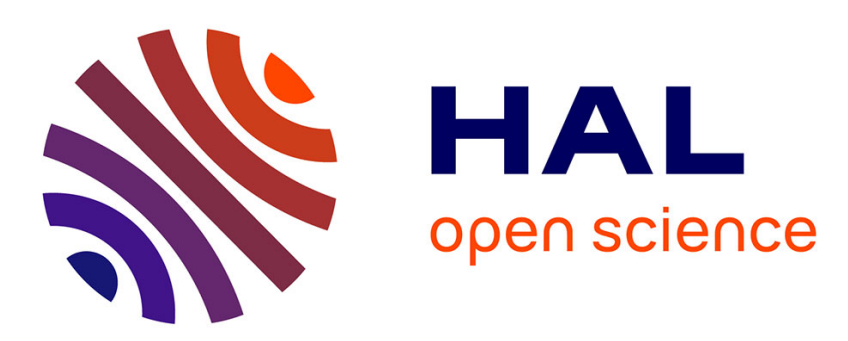

\title{
Evaluation of a Patient-Specific Finite-Element Model to Simulate Conservative Treatment in Adolescent Idiopathic Scoliosis
}

\author{
Claudio Vergari, Gwenael Ribes, Benjamin Aubert, Clayton Adam, Lotfi \\ Miladi, Kariman Abelin-Genevois, Philippe Rouch, Wafa Skalli
}

\section{To cite this version:}

Claudio Vergari, Gwenael Ribes, Benjamin Aubert, Clayton Adam, Lotfi Miladi, et al.. Evaluation of a Patient-Specific Finite-Element Model to Simulate Conservative Treatment in Adolescent Idiopathic Scoliosis. Spine Deformity, 2015, 3 (1), pp.4-11. 10.1016/j.jspd.2014.06.014 . hal-02460811

\section{HAL Id: hal-02460811 https://hal.science/hal-02460811}

Submitted on 30 Jan 2020

HAL is a multi-disciplinary open access archive for the deposit and dissemination of scientific research documents, whether they are published or not. The documents may come from teaching and research institutions in France or abroad, or from public or private research centers.
L'archive ouverte pluridisciplinaire HAL, est destinée au dépôt et à la diffusion de documents scientifiques de niveau recherche, publiés ou non, émanant des établissements d'enseignement et de recherche français ou étrangers, des laboratoires publics ou privés. 


\title{
Biomechanics
}

\section{Evaluation of a Patient-Specific Finite-Element Model to Simulate Conservative Treatment in Adolescent Idiopathic Scoliosis}

\author{
Claudio Vergari, $\mathrm{PhD}^{\mathrm{a}, *}$, Gwenael Ribes, MEng ${ }^{\mathrm{a}}$, Benjamin Aubert, MEng ${ }^{\mathrm{a}}$, \\ Clayton Adam, $\mathrm{PhD}^{\mathrm{a}}$, Lotfi Miladi, $\mathrm{MD}^{\mathrm{b}}$, Brice Ilharreborde, $\mathrm{MD}^{\mathrm{c}}$, \\ Kariman Abelin-Genevois, $\mathrm{MD}^{\mathrm{d}}$, Philippe Rouch, $\mathrm{PhD}^{\mathrm{a}}$, Wafa Skalli, $\mathrm{PhD}^{\mathrm{a}}$ \\ ${ }^{\mathrm{a}}$ Arts et Metiers ParisTech, LBM, 151 bd de l'Hopital, 75013 Paris, France \\ ${ }^{\mathrm{b}}$ Department of Pediatric Orthopedics, Necker Enfants Malades Hospital, AP-HP, 149 rue de Sevres, 75743 Paris Cedex 15, France \\ ${ }^{\mathrm{c}}$ Pediatric Orthopaedics Department, Robert Debré Hospital, AP-HP, Paris Diderot University, 48 Bd Sérurier, 75019 Paris, France \\ d Department of Pediatric Orthopedics, Hospices Civils de Lyon, Claude Bernard Lyon 1 University, Lyon, \\ France
}

\begin{abstract}
Study design: Retrospective validation study.

Objectives: To propose a method to evaluate, from a clinical standpoint, the ability of a finite-element model (FEM) of the trunk to simulate orthotic correction of spinal deformity and to apply it to validate a previously described FEM.

Summary of background data: Several FEMs of the scoliotic spine have been described in the literature. These models can prove useful in understanding the mechanisms of scoliosis progression and in optimizing its treatment, but their validation has often been lacking or incomplete. Methods: Three-dimensional (3D) geometries of 10 patients before and during conservative treatment were reconstructed from biplanar radiographs. The effect of bracing was simulated by modeling displacements induced by the brace pads. Simulated clinical indices (Cobb angle, T1-T12 and T4-T12 kyphosis, L1-L5 lordosis, apical vertebral rotation, torsion, rib hump) and vertebral orientations and positions were compared to those measured in the patients' 3D geometries.

Results: Errors in clinical indices were of the same order of magnitude as the uncertainties due to 3D reconstruction; for instance, Cobb angle was simulated with a root mean square error of $5.7^{\circ}$, and rib hump error was $5.6^{\circ}$. Vertebral orientation was simulated with a root mean square error of $4.8^{\circ}$ and vertebral position with an error of $2.5 \mathrm{~mm}$.

Conclusions: The methodology proposed here allowed in-depth evaluation of subject-specific simulations, confirming that FEMs of the trunk have the potential to accurately simulate brace action. These promising results provide a basis for ongoing 3D model development, toward the design of more efficient orthoses.
\end{abstract}

Keywords: Brace; Adolescent idiopathic scoliosis; Simulation; 3D reconstruction; Biplanar radiography

\section{Introduction}

Adolescent idiopathic scoliosis (AIS) is a three-dimensional (3D) deviation of the spinal axis [1], which develops in most cases during adolescence and can lead to functional impairment. The scoliotic deformity is usually quantified radiographically using the Cobb angle [2], a two-dimensional (2D) parameter measured in the frontal plane that only suffices for a superficial description of the scoliosis. Surgery is often required at skeletal maturity in the case of severe scoliosis (Cobb angle higher than $45^{\circ}$ ), whereas conservative treatment (bracing or casting) is preferred when progressive scoliosis is diagnosed earlier $\left(\mathrm{Cobb}\right.$ angle $\left.20^{\circ}-35^{\circ}\right)$. The challenge of orthotic treatment is to stop or slow down the progression of the spinal curvature prior to skeletal maturity, in order to avoid surgery. Orthotic treatments are widely used for progressive curves; their effectiveness has often been questioned [3,4], but a recent study by Weinstein et al. [5] showed that bracing could 
significantly reduce scoliosis progression, especially in those patients with a high level of compliance to brace wear.

Low-dose biplanar radiographs can be used in routine clinical practice to assess patient-specific spinal geometry during conservative treatment, allowing better description of the correction in three dimensions [6]. Testing different brace designs in order to optimize correction, however, requires multiple radiographic images; radiation doses can then accumulate over the several years that are often needed for this treatment.

Subject-specific biomechanical models can help to better understand the mechanisms of bracing [7] and ultimately to plan the optimal conservative treatment for a specific subject, thus reducing the number of X-rays needed. Model validation, however, remains a challenge [8] because of the difficulties of obtaining in vivo data to compare to the simulation output. Several studies have used finite-element models (FEMs) for bracing simulation without thoroughly evaluating model consistency [9-11], although attempts to compare simulation and experimental measurements have been performed, generally in a very small number of patients, using $2 \mathrm{D}$ or $3 \mathrm{D}$ geometric parameters [12-15]. Cobb angle was the main parameter evaluated, whereas lordosis and kyphosis were only evaluated in one study with six patients [15]. Rib hump, frontal shift, and sagittal shift were only assessed in one patient [13]. Vertebral position $[12,14]$ and plane of maximum deformation were evaluated in fewer than four patients [12-14]. Transverse plane parameters (vertebral orientation, apical rotation, torsion) and rib hump are of clinical importance [16], but they have often been neglected in previous studies.

The goal of this study was to propose a method for detailed evaluation of an FEM for simulating bracing effects in AIS patients. For that purpose, simulated key geometric indices (including transverse plane deformity parameters) were compared with those measured in vivo.

\section{Methods}

\section{General principle}

The evaluation method aimed to compare the simulated correction of the trunk induced by the orthosis with the actual correction as measured on in-brace radiographs. Patient- specific FEMs of the trunk were built from the standing radiograph of the patient's trunk before and during treatment. Orthosis action was simulated in the model by applying local displacements at each pad position, as described below. Simulated clinical indices were then calculated from the deformed FEM shape after simulation. Radiologic indices were measured from the $3 \mathrm{D}$ reconstruction of the patient's actual geometry of spine and ribcage within the orthosis. These two sets of clinical indices were then compared to determine the simulation error.

\section{Subjects}

Ten AIS patients, nine girls and one boy, with a mean Cobb angle of $25^{\circ} \pm 13^{\circ}$ (range $13^{\circ}-54^{\circ}$ ) were retrospectively included (Table 1). Low-dose biplanar radiographs (EOS system; EOS imaging, Paris, France) were performed in the standing position both before and during casting $(\mathrm{n}=5$, $\mathrm{P} 1-\mathrm{P} 5)$ or bracing $(\mathrm{n}=5, \mathrm{P} 6-\mathrm{P} 10)$; these radiographs were performed as part of clinical routine and were included retrospectively after approval of the local ethics committees. Both braces and casts were adjusted according to the clinician's indications. The delay between the two acquisitions (without and with brace) was 3 months or less (Table 1).

\section{D Geometry}

For each patient, the 3D geometry of the pelvis, spine, and ribcage was reconstructed using previously described techniques [17-22] by experienced users. Briefly, these methods allow the personalization of parametric models of bony structures (vertebrae, ribs, pelvis), based on transversal and longitudinal inferences, to fit the radiographic images of the patient (posteroanterior and lateral). A first reconstruction can be obtained by digitizing specific anatomic landmarks in order to quickly calculate clinical parameters; for the present study, however, each model was manually adjusted to fit the original radiographs for maximum accuracy.

It was hypothesized that vertebrae were not deformed by the orthosis action, implying that the spinal curve correction was due to vertebral displacement and soft tissue deformation alone. Therefore, in order to minimize the reconstruction

Table 1

Characteristics of patients before orthotic treatment. Clinical indices were calculated from the 3D reconstruction without the orthosis.

\begin{tabular}{|c|c|c|c|c|c|c|c|c|c|c|c|}
\hline & Gender & $\begin{array}{l}\text { Orthosis } \\
\text { type }\end{array}$ & $\begin{array}{l}\text { Time between } \\
\text { the two acquisitions }\end{array}$ & $\begin{array}{l}\text { Risser } \\
\text { grade }\end{array}$ & $\begin{array}{l}\text { Cobb } \\
\text { angle }\left({ }^{\circ}\right)\end{array}$ & $\begin{array}{l}\text { Lordosis } \\
\text { L1-L5 }\left(^{\circ}\right)\end{array}$ & $\begin{array}{l}\text { Kyphosis } \\
\mathrm{T} 1-\mathrm{T} 12\left(^{\circ}\right)\end{array}$ & $\begin{array}{l}\text { Kyphosis } \\
\mathrm{T} 4-\mathrm{T} 12\left(^{\circ}\right)\end{array}$ & $\begin{array}{l}\text { Maximum rib } \\
\text { hump }\left(^{\circ}\right) \text { (level) }\end{array}$ & $\begin{array}{l}\text { Apical } \\
\text { rotation }\left(^{\circ}\right)\end{array}$ & $\begin{array}{l}\text { Torsion } \\
\text { Index }\left({ }^{\circ}\right)\end{array}$ \\
\hline P1 & $\mathrm{F}$ & Cast & Same day & 0 & 13.3 & 64.4 & 42.7 & 33.4 & 12.4 (T10) & 4.6 & 3.6 \\
\hline $\mathrm{P} 2$ & $\mathrm{~F}$ & Cast & Same day & 5 & 24.5 & 42.3 & 36.3 & 40.5 & $8.2(\mathrm{~T} 4)$ & 15.2 & 3.8 \\
\hline P3 & $\mathrm{F}$ & Cast & 2 days & 2 & 53.7 & 54.3 & 30.0 & 9.1 & $16.1(\mathrm{~T} 10)$ & 14.8 & 17.9 \\
\hline P4 & $\mathrm{F}$ & Cast & 1 day & 0 & 39.8 & 57.3 & 26.2 & 2.8 & 13.4 (T10) & 10.1 & 5.9 \\
\hline P5 & M & Cast & 1 day & 2 & 12.8 & 62.0 & 62.3 & 44.0 & 10.0 (T6) & 7.3 & 2.4 \\
\hline P6 & $\mathrm{F}$ & Brace & 2 months & 0 & 17.7 & 51.8 & 41.7 & 39.5 & 4.8 (T7) & 7.7 & 1.7 \\
\hline P7 & $\mathrm{F}$ & Brace & Same day & 0 & 15.3 & 20.6 & 23.4 & 34.0 & 7.6 (T9) & 13.8 & 4.9 \\
\hline P8 & $\mathrm{F}$ & Brace & 3 months & 0 & 27.3 & 38.1 & 9.8 & 6.2 & -1.1 (T9) & 7.4 & 9.8 \\
\hline P9 & $\mathrm{F}$ & Brace & 2 months & 0 & 27.6 & 65.0 & 36.1 & 29.0 & 10.8 (T6) & 5.1 & 4.5 \\
\hline P10 & $\mathrm{F}$ & Brace & 2 months & 0 & 21.3 & 43.5 & 24.2 & 20.8 & 8.3 (T8) & 17.9 & 2.3 \\
\hline
\end{tabular}

3D, three-dimensional. 
errors in vertebral shape, the average shape of each vertebra and the pelvis was calculated between the two reconstructions (with/without brace) and used for simulations. This actually improves the model's degree of personalization, assuming that growth did not significantly affect vertebral anatomy in the maximum 3-month delay between examinations, since it reduces the reconstruction errors. Ribs, on the other hand, were not averaged since they could be deformed by the brace action.

\section{Finite-element model}

The personalized FEM (5,188 elements, 1,997 nodes), implemented in ANSYS V11 (Ansys Inc., Canonsburg, PA), has been previously described [23-27]. The main components of the model were the pelvis, sacrum, thoracic and lumbar vertebrae, intervertebral discs, ligaments, and ribcage;
Table 2

Main elements used in the model for the main structural components and their material properties.

\begin{tabular}{lllll}
\hline Item & Element & $E(\mathrm{MPa})$ & $\nu(-)$ & Reference \\
\hline Vertebral bodies & Beam & 1,000 & 0.3 & {$[23]$} \\
Intervertebral discs & Beam & $1-35$ & 0.45 & {$[34]$} \\
Pedicles & Beam & 5,000 & 0.3 & {$[23]$} \\
Spinous processes & Beam & 3,500 & 0.3 & {$[23]$} \\
Posterior arches & Beam & 5,000 & 0.3 & {$[23]$} \\
Transverse processes & Beam & 3,500 & 0.3 & {$[23]$} \\
Articular facets & Shell & 5,000 & 0.3 & {$[23]$} \\
Apophysis & Beam & 5,000 & 0.3 & {$[23]$} \\
Sternum & Beam & 10,000 & 0.2 & {$[23]$} \\
Ribs & Beam & $2,790-7,440$ & 0.1 & {$[28,29]$} \\
Costovertebral joints & Beam & $5-50$ & 0.2 & {$[25]$} \\
Costal cartilage & Beam & 480 & 0.1 & {$[23]$} \\
Intercostal ligaments & Cable & Multilinear & 0.2 & {$[35]$} \\
\hline
\end{tabular}

(adapted from Descrimes et al. [23])
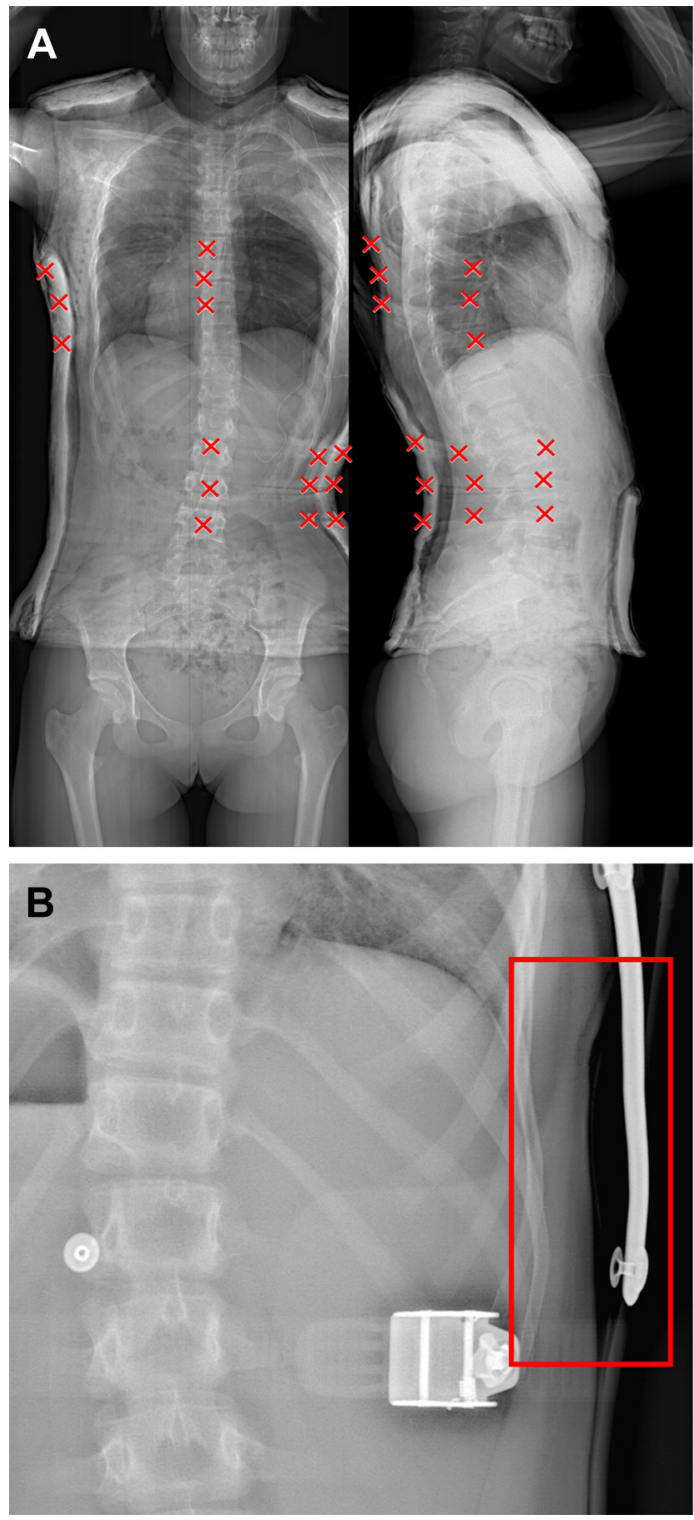

Fig. 1. (A) Multiplication $(\times)$ symbols show radio-opaque markers embedded in cast pad regions. (B) Rectangle showing an example of brace pressure region identified by soft tissue compression. (C) Sets of nodes on the finite-element model describing pressure regions. 
material properties are summarized in Table 2. A custommade algorithm allowed transformation of vertebral volume models to beam models.

The ribcage was composed of ribs, costal cartilage, intercostal membrane, intercostal ligaments, sternum, and costovertebral and costotransverse joints. Ribs and costal cartilage were modeled by elastic beams, and in the present study they were improved from previous works by adapting their Young modulus according to the patient's Risser grade [28], whereas their second moments of area were adapted according to the vertebral level from an existing database of scoliotic adolescent rib morphology [29]. Intercostal ligaments were represented by cable elements and the intercostal membrane by linear elastic shells. The sternum was modeled with linear elastic shell elements. The ribcage was connected to vertebrae by the costovertebral and costotransverse joints, as previously characterized [10,25].

\section{Simulation}

A preliminary step of each simulation was the displacement of the T1 vertebra and of the pelvis to the target position (ie, its position in the in-brace configuration), in order to simulate the tendency of the subject to maintain balance. The pelvis was then fixed whereas the $\mathrm{T} 1$ vertebra was allowed to translate in the vertical axis during the application of brace action. This action was simulated by applying local displacements induced by the orthotic pads, as described below.

Radio-opaque markers were embedded in the casts in order to detect pad regions on the radiographs (Fig. 1A). For the other four patients wearing a brace, pressure regions

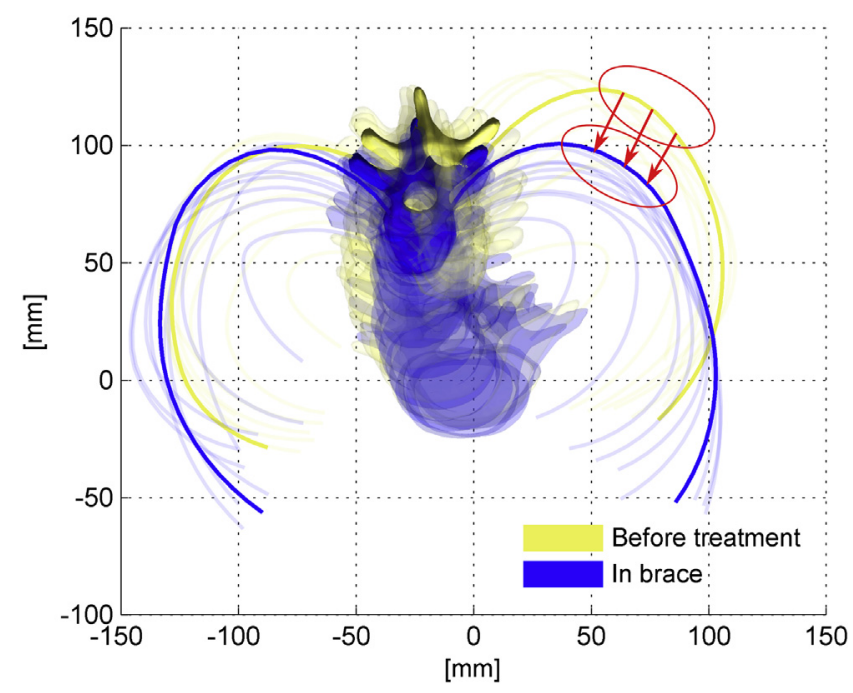

Fig. 2. Principle of application of boundary conditions: displacements were calculated as position differences of pad regions (oval outlines in the figure) between the before-treatment and in-brace $3 \mathrm{D}$ reconstructions. These displacements were then applied to the finite-element model before treatment. Only the seventh left rib is highlighted in this example, although pad regions usually spanned at least three ribs. were directly identified on the radiographs by observing external envelope deformations (Fig. 1B). Sets of nodes corresponding to these pressure regions were then manually identified on the model, as shown in Figure 1C.

Figure 2 shows an example of displacements applied to the model to simulate the orthosis action on a rib. Displacements were calculated as the difference between pad region position before treatment and in-brace; the average displacements of each pad region were then applied to the in-brace model in order to simulate brace action. After the simulation, the final geometry was retransformed in the volume models in order to calculate clinical indices.

\section{Calculation of clinical indices}

Clinical indices were calculated in both the simulated and actual 3D geometry. Clinical indices were calculated in the patient frame of reference defined by the pelvis.

Rib hump was defined as the angle between the anteroposterior axis of the local coordinate system of the vertebra and the segment joining the most posterior sections of the ribs. It was calculated at each vertebral level in the reconstruction without the orthosis, and the vertebral level corresponding to maximum rib hump was noted. The rib hump at this same level was then calculated on the reconstruction with the orthosis and on the simulated geometry in order to assess rib hump correction by the orthosis.

Torsion index was calculated as the mean of the absolute value of the sum of axial intervertebral rotations in inferior and superior semicurvatures [30].

\section{Statistics}

The precision $\left(2 \mathrm{RMS}_{\mathrm{SD}}\right)$ for measurement of vertebral position and orientation, and for calculation of clinical indices based on 3D reconstruction from biplanar radiographs, has been previously determined [19,20] (Table 3). When comparing two 3D reconstructions, the minimal error

Table 3

Uncertainty of clinical indices, vertebral positions, and orientations in 3D reconstruction.

\begin{tabular}{lll}
\hline & $\begin{array}{l}\text { Reconstruction } \\
\text { uncertainty [19-21] }\end{array}$ & $\begin{array}{l}\text { Error } \\
\text { tolerance }\end{array}$ \\
\hline Kyphosis T1-T12 $\left(^{\circ}\right)$ & 5.5 & 7.8 \\
Kyphosis T4-T12 $\left(^{\circ}\right)$ & 3.8 & 5.4 \\
Lordosis L1-L5 $\left(^{\circ}\right)$ & 4.6 & 6.5 \\
Cobb angle $\left({ }^{\circ}\right)$ & 3.1 & 4.4 \\
Apical rotation $\left({ }^{\circ}\right)$ & 3.4 & 4.8 \\
Torsion index $\left({ }^{\circ}\right)$ & 4.0 & 5.7 \\
Rib hump $\left({ }^{\circ}\right)$ & 5.0 & 7.1 \\
Vertebral position & $1.2,1.1,0.8$ & $1.7,1.6,1.1$ \\
$\quad \mathrm{X}, \mathrm{Y}, \mathrm{Z}(\mathrm{mm})$ & & $3.4,3.3,5.5$ \\
Vertebral orientation & $2.4,2.3,3.9$ & \\
$\quad$ Lateral, sagittal, axial $\left({ }^{\circ}\right)$ & & \\
\hline \multicolumn{2}{l}{ 3D, three-dimensional. } & \\
$\quad$ Note: Tolerances in the present work were determined by considering \\
the propagation of uncertainty.
\end{tabular}


Table 4

Differences between measured and simulated clinical indices (measured in-brace values between parentheses) and RMSE.

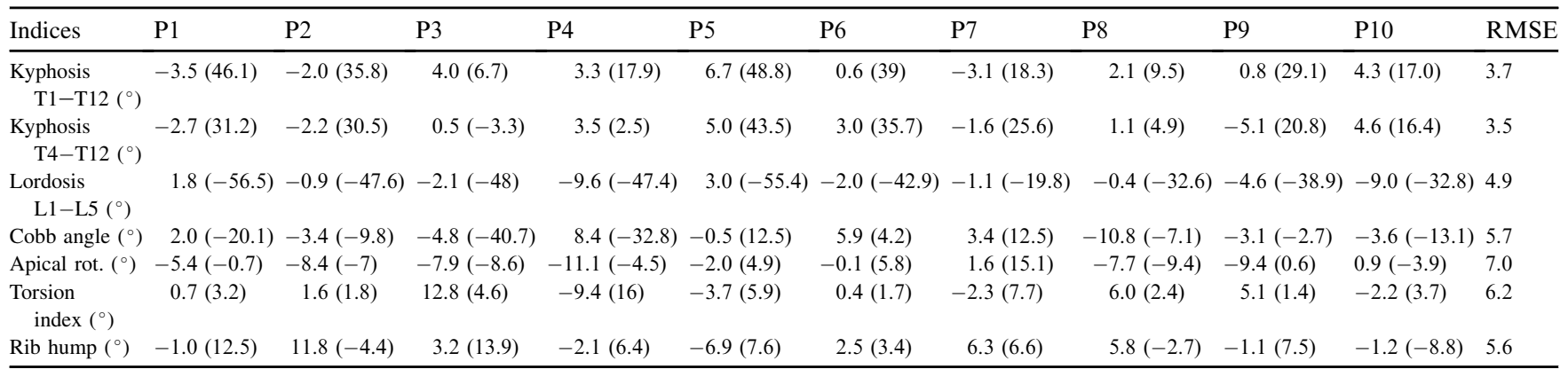

RMSE, root mean square error between simulation and actual measurements.

that can be expected is $\varepsilon=\sqrt{2 \cdot\left(2 R M S_{S D}\right)^{2}}$ because both reconstructions are affected by the same uncertainty [31]. Therefore, the differences between simulated and actual clinical indices were compared to tolerance values thus calculated (Table 3).

The root mean square errors (RMSEs) of vertebral orientation and position were also calculated by pooling all vertebral levels to evaluate overall geometry. Pearson correlation coefficients were calculated between actual and simulated vertebral displacements; significance was set at $\mathrm{p}$ $<.05$. Calculations were performed with Matlab 2011 (Mathworks, Natick, MA).

\section{Results}

Differences between radiologic and simulated clinical indices for each patient are presented in Table 4, as well as the measured values with the orthosis; $77 \%$ of the simulated values were in the tolerance error interval, whereas all

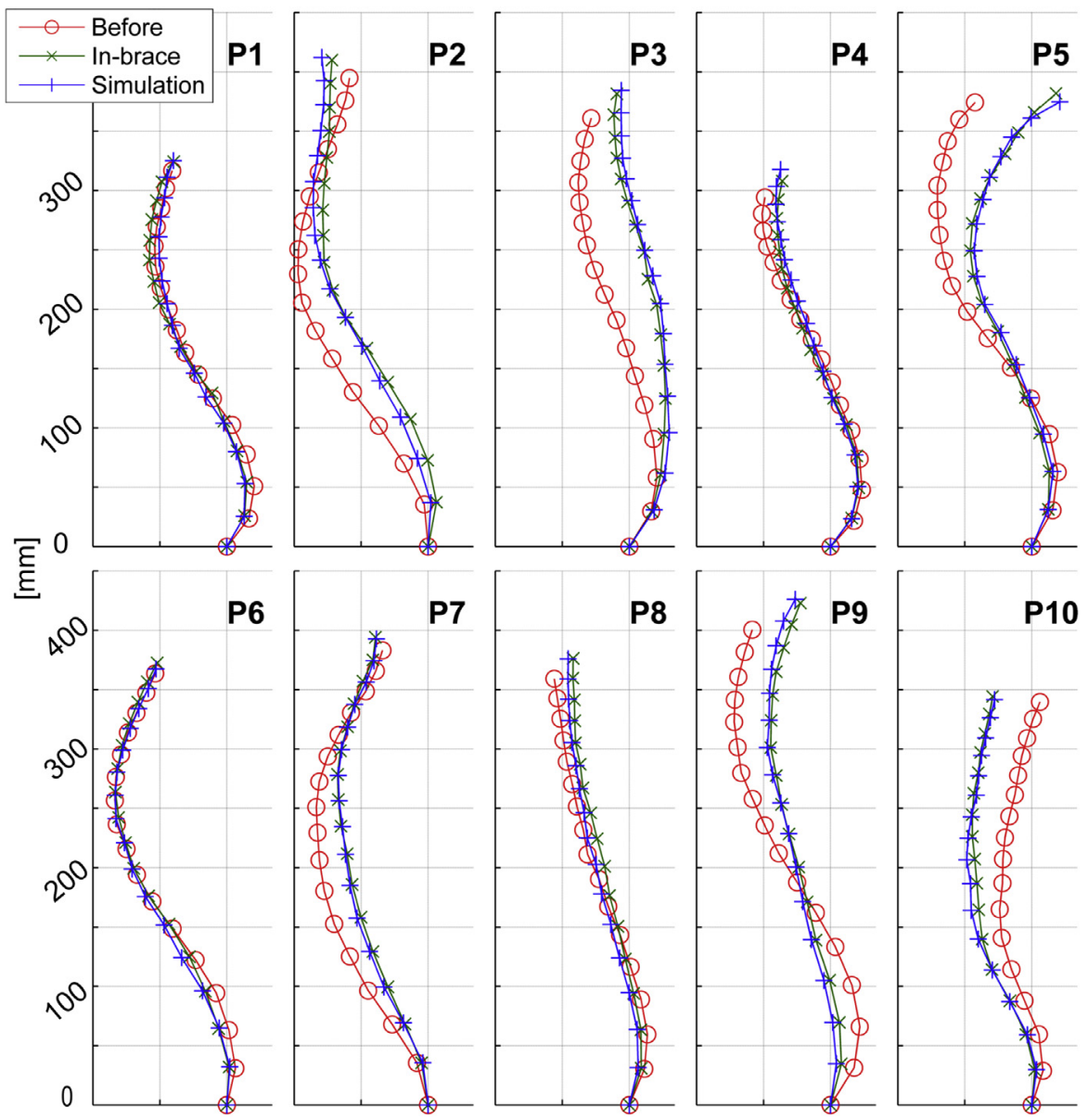

Fig. 3. Vertebral positions and spine midlines before treatment, in-brace and in simulated geometry: lateral views. 

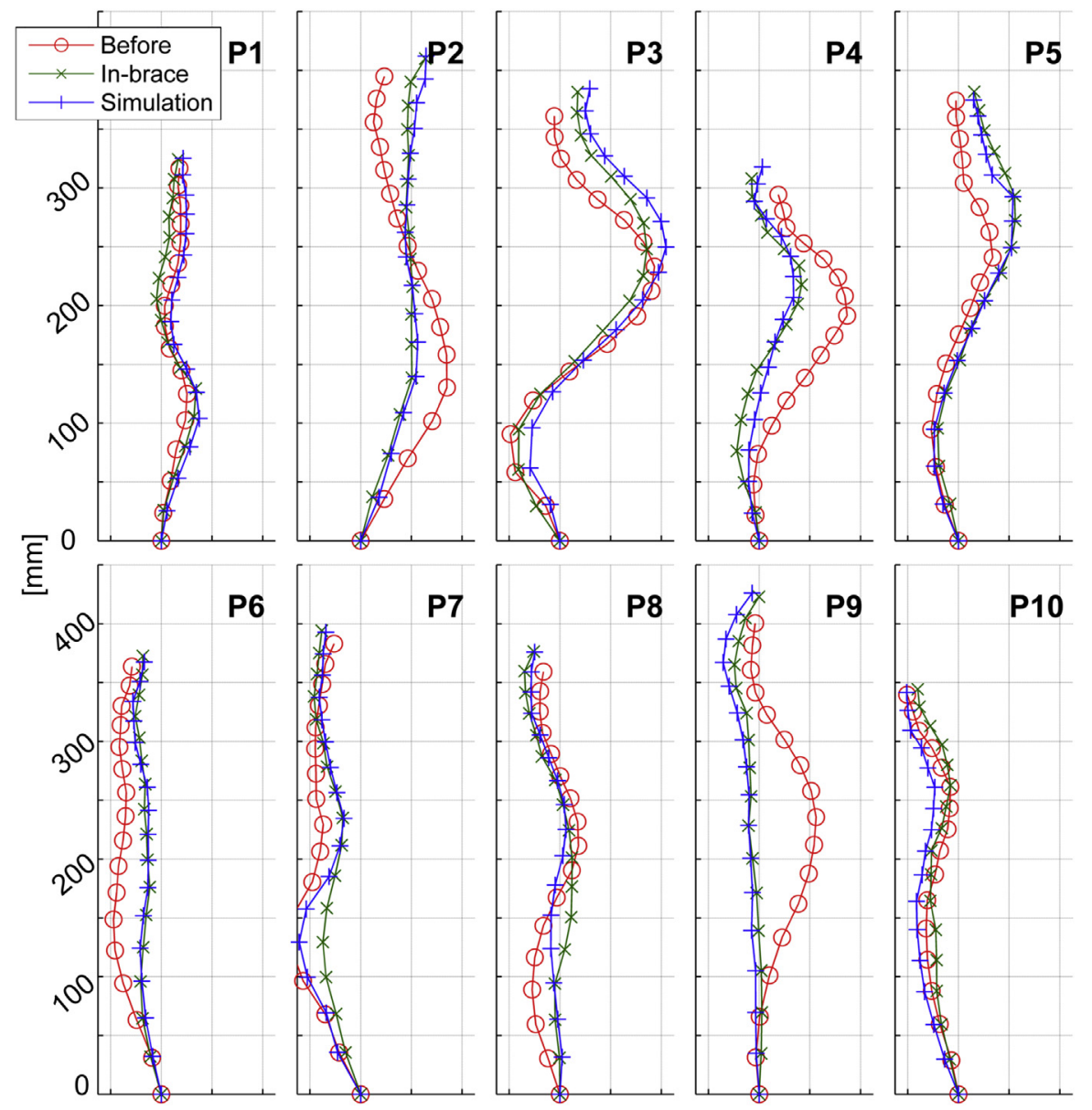

Fig. 4. Vertebral positions and spine midlines before treatment, in-brace and in simulated geometry: posterior views.

Table 5

Root mean square errors between rotation and position (all vertebral levels pooled) in the 3D reconstruction and the simulation for each patient, followed by global RMSE.

\begin{tabular}{llllllllllll}
\hline & P1 & P2 & P3 & P4 & P5 & P6 & P7 & P8 & P9 & P10 & RMSE \\
\hline Frontal rotation $\left({ }^{\circ}\right)$ & 2.8 & 3.5 & 2.9 & 4.0 & 2.5 & 2.0 & 2.4 & 3.9 & 1.8 & 3.1 & 3.0 \\
Lateral rotation $\left(^{\circ}\right)$ & 4.7 & 2.1 & 2.5 & 5.2 & 4.2 & 2.4 & 1.6 & 2.7 & 2.7 & 3.1 & 3.3 \\
Axial rotation $\left(^{\circ}\right)$ & 3.3 & 4.8 & 4.5 & 17.0 & 5.4 & 4.2 & 4.8 & 4.9 & 6.1 & 5.3 & 7.1 \\
X $(\mathrm{mm})$ & 3.5 & 2.8 & 1.3 & 1.8 & 2.3 & 1.4 & 1.5 & 1.4 & 1.5 & 2.7 & 2.1 \\
Y (mm) & 2.9 & 2.1 & 1.7 & 4.6 & 1.5 & 1.3 & 4.6 & 3.3 & 1.4 & 2.3 & 2.8 \\
Z (mm) & 1.9 & 0.9 & 0.8 & 6.1 & 2.1 & 2.7 & 0.7 & 0.8 & 1.2 & 1.6 & 2.4 \\
\hline
\end{tabular}

RMSE, root mean square error between simulation and actual measurements; 3D, three-dimensional.

values are of the same order of magnitude as the tolerance. For instance, the RMSE of Cobb angle was $5.7^{\circ}$ (against an error tolerance of $4.4^{\circ}$ ), and the RMSE of rib hump was $5.6^{\circ}$ (tolerance: $7.1^{\circ}$ ). Only axial rotation was $2^{\circ}$ higher than the tolerance $\left(7^{\circ} \mathrm{RMSE}\right.$ against $4.8^{\circ}$ tolerance).

Schematic representations of vertebral positions and spinal midlines are given in Figures 3 and 4. Differences in vertebral orientation and positions between the simulation and the reconstruction within the brace are presented in Table 5; they are of the same order of magnitude as the reconstruction tolerances.
Correlation coefficients between simulated and actual vertebral positions were higher than $0.8(\mathrm{p}<.01)$ for all patients.

\section{Discussion}

This study proposes a method to evaluate the relevance of a patient-specific FEM for the simulation of orthotic treatment of spinal deformities. Orthotic treatment was simulated and evaluated, but the method described could equally well be applied to evaluate simulations of other spine and/or ribcage treatments. Key 3D clinical indices 
were measured after simulation and compared to the in vivo values obtained with biplanar radiographs. These indices are necessary for a complete clinical and geometric description of the scoliotic trunk, and are therefore essential when evaluating simulation performance.

The FEM utilized in this study could reproduce the brace effect on the trunk to within acceptable error limits in nine patients, both in terms of clinical indices (Table 4) and spine geometry (Table 5), which were of the same order of magnitude as the uncertainties due to the reconstruction. The tolerance values that were adopted as a reference in this study (Table 3) can be considered the lowest theoretical errors attainable, because they represent the uncertainty that can be expected when comparing two 3D reconstructions; these tolerances imply that the simulation is as accurate as the $3 \mathrm{D}$ reconstruction on which it is based. Moreover, it can be assumed that errors that are lower than these tolerances are not significant.

Two main limitations affect the FEM evaluated in the present study; first, gravitational forces [32] and muscle contributions $[9,33]$ were not explicitly implemented in the model. Therefore, the agreement between radiologic indices and simulation is only related to the passive mechanical response of the spine-ribcage complex. This limitation, however, only affects the realism of the interaction between the brace and the patient's voluntary response, which is beyond the scope of this article. Viscoelastic behavior of soft tissues was neglected as well, but this aspect probably does not play an important role in brace action, which is slow and the effects of which are measured after long delays.

Second, orthosis action was implemented by imposing known displacements to selected nodes, in order to simulate the pad pressure; this technique, however, does not allow prediction of the treatment action without (at least partial) a priori knowledge of the target results. Therefore, the FEM was evaluated here in terms of its ability to capture the geometric deformations of the spine and ribcage resulting from known brace pad displacements; in other words, this work aimed at validating the behavior of the trunk biomechanical model. Including an explicit description of the pads at this stage would have improved the realism of the brace simulation, but it would have also increased the sources of variability for the validation of the biomechanical model itself. Explicit brace modeling and analysis of contact forces could be implemented in further analysis, which should include muscular action and gravity as well; this is an essential step, especially when personalizing or designing braces in order to account for brace tolerability and comfort.

The ribcage is a particularly complicated mechanical structure, the response of which depends on a large set of geometric and mechanical parameters. This study included a more accurate personalization of the spine and ribcage geometry than has been previously implemented, as well as an adaptation of the mechanical properties of the ribs according to the age of the subject. Personalization of mechanical properties of the intervertebral discs and costovertebral joints could be not introduced in the present study, since reliable techniques for in vivo mechanical evaluation of these structures are still lacking; a sensitivity study will help determine which mechanical properties are determinant for the simulation. Rib hump was simulated with an error of $6.4^{\circ}$ [range $1^{\circ}-12^{\circ}$ ], which is similar to the $7^{\circ}$ error that was previously measured on one patient in the study performed by Périé et al. [13]. Rib hump differences between actual and simulated treatment could be related either to ribs and ribcage behavior (and therefore to the simulation of the pad action), or to the modeling of the costovertebral joints.

Errors in vertebral positions and clinical indices were relatively small. Kyphosis (T1-T12) and lordosis were simulated with average absolute errors of $4^{\circ}$ and $5^{\circ}$, respectively, which is lower than the errors obtained by Desbiens et al. [15] $\left(9.2^{\circ}\right.$ and $13^{\circ}$ mean difference, respectively). While mean errors remained within the range of uncertainty, some patients had higher differences; these could be due to material properties, which were not subject specific in the current study because of the abovementioned limitations in determining subject-specific material properties.

Desbiens et al. [15] observed mean errors in Cobb angle of $4.4^{\circ}$, Périé et al. [12] obtained $3.9^{\circ}$ in 6 patients, whereas Chou et al. $3.5^{\circ}$ [14]. A higher error of $8^{\circ}$ was found by Périé et al. [13], but it was based on the evaluation of a single patient. In the present study, Cobb angle errors were lower than $6^{\circ}$ (average $6^{\circ}$ ) except for patients $\mathrm{P} 4$ and P8.

As for vertebral positions, correlation coefficients indicated good agreement between simulation and in vivo measurements in nine patients. Similar agreements (coefficients of 0.9 and 0.99 , respectively) were also measured in the studies by Périé et al. [12] and Chou et al. [14], but they were obtained in fewer than 4 patients. Vertebral orientations, apical rotation, and torsion index were measured in the present study to complete the model validation in the transverse plane. Analysis of the literature shows that previous studies were often validated on a very small number of subjects (less than or equal to six). This study was conducted on slightly larger number of subjects, although they received two different treatments (five were treated by cast and five by bracing). The results of this study now justify a larger multicentric data collection to further validate the model and better understand brace action.

The comparison of simulation results to in vivo radiographic measurements suggests that the approach presented in this study could be used to assess the relevance of patient-specific bracing simulations. This method could also serve as a benchmark for sensitivity studies in which the relationship between biomechanical model parameters and clinically measured indices is of interest.

The ability of the patient-specific FEM approach for simulating a wide range of clinical indices appears to 
justify future research, in particular in the areas of spinal deformity brace simulation and planning.

Research Ethics Committee: Radiographs were performed as part of clinical routine and were included retrospectively after approval of the local ethical committees.

\section{Acknowledgments}

The authors are grateful to the ParisTech BiomecAM chair program on subject-specific musculoskeletal modeling for funding (with the support of Proteor, ParisTech, and Yves Cotrel Foundations), and to EOS imaging for logistic support in data collection.

\section{References}

[1] Dubousset J. [Idiopathic scoliosis. Definition-pathology-classification-etiology]. Bulletin de l'Academie nationale de medecine 1999;183:699-704.

[2] Carman DL, Browne RH, Birch JG. Measurement of scoliosis and kyphosis radiographs. Intraobserver and interobserver variation. J Bone Joint Surg Am 1990;72:328-33.

[3] Negrini S, Minozzi S, Bettany-Saltikov J, et al. Braces for idiopathic scoliosis in adolescents. Cochrane Database Syst Rev 2010:CD006850.

[4] Nachemson AL, Peterson LE. Effectiveness of treatment with a brace in girls who have adolescent idiopathic scoliosis. A prospective, controlled study based on data from the brace study of the scoliosis research society. J Bone Joint Surg Am 1995;77:815-22.

[5] Weinstein SL, Dolan LA, Wright JG, Dobbs MB. Effects of bracing in adolescents with idiopathic scoliosis. N Engl J Med 2013;369:1512-21.

[6] Courvoisier A, Drevelle X, Vialle R, et al. 3D analysis of brace treatment in idiopathic scoliosis. Eur Spine J 2013;22:2449-55.

[7] Wang W, Baran GR, Betz RR, et al. The use of finite element models to assist understanding and treatment for scoliosis: a review paper. Spine Deformity 2014;2:10-27.

[8] Jalalian A, Gibson I, Tay EH. Computational biomechanical modeling of scoliotic spine: Challenges and opportunities. Spine Deformity 2013;1:401-11.

[9] Wynarsky GT, Schultz AB. Optimization of skeletal configuration: studies of scoliosis correction biomechanics. J Biomech 1991;24:721-32.

[10] Gignac D, Aubin CÉ, Dansereau J, Labelle H. Optimization method for 3D bracing correction of scoliosis using a finite element model. Eur Spine J 2000;9:185-90.

[11] Clin J, Aubin C-E, Parent S, et al. Comparison of the biomechanical $3 \mathrm{D}$ efficiency of different brace designs for the treatment of scoliosis using a finite element model. Eur Spine J 2010;19:1169-78.

[12] Perie D, Aubin CE, Petit Y, et al. Personalized biomechanical simulations of orthotic treatment in idiopathic scoliosis. Clin Biomech (Bristol, Avon) 2004;19:190-5.

[13] Perie D, Aubin CE, Lacroix M, et al. Biomechanical modelling of orthotic treatment of the scoliotic spine including a detailed representation of the brace-torso interface. Med Biol Eng Comput 2004;42:339-44.

[14] Chou WK, Liu CL, Liao YC, et al. Using finite element method to determine pad positions in a Boston brace for enhancing corrective effect on scoliotic spine: a preliminary analysis. J Med Biol Eng 2012;32:29-35.

[15] Desbiens-Blais F, Clin J, Parent S, et al. New brace design combining $\mathrm{CAD} / \mathrm{CAM}$ and biomechanical simulation for the treatment of adolescent idiopathic scoliosis. Clin Biomech 2012;27:999-1005.
[16] Courvoisier A, Drevelle X, Dubousset J, Skalli W. Transverse plane 3D analysis of mild scoliosis. Eur Spine J 2013;22:2427-32.

[17] Ilharreborde B, Dubousset J, Skalli W, Mazda K. Spinal penetration index assessment in adolescent idiopathic scoliosis using EOS low-dose biplanar stereoradiography. Eur Spine J 2013;22: 2438-44.

[18] Jolivet E, Sandoz B, Laporte S, et al. Fast 3D reconstruction of the rib cage from biplanar radiographs. Med Biol Eng Comput 2010;48: $821-8$.

[19] Humbert L, De Guise JA, Aubert B, et al. 3D reconstruction of the spine from biplanar X-rays using parametric models based on transversal and longitudinal inferences. Med Eng Phys 2009;31:681-7.

[20] Aubert B, Vergari C, Ilharreborde B, et al. 3D reconstruction of rib cage geometry from biplanar radiographs using a statistical parametric model approach. Computer Methods Biomech Biomed Eng; In press.

[21] Aubert B, Vergari C, Ilharreborde B, Skalli W. Reconstruction of the rib cage geometric properties from biplanar radiographs. In: 48th Annual Meeting of the Scoliosis Research Society, Lyon (France), 2013.

[22] Courvoisier A, Ilharreborde B, Constantinou B, et al. Evaluation of a three-dimensional reconstruction method of the rib cage of mild scoliotic patients. Spine Deformity 2013;1:321-7.

[23] Descrimes JL, Aubin CE, Skalli W, et al. Introduction des facettes articulaires dans une modélisation par éléments finis de la colonne vertébrale et du thorax scoliotique : Aspects mécaniques. Rachis 1995;7:301-14.

[24] Aubin CE, Descrimes JL, Dansereau J, et al. [Geometrical modeling of the spine and the thorax for the biomechanical analysis of scoliotic deformities using the finite element method]. Ann Chir 1995;49: 749-61.

[25] Lemosse D, Le Rue O, Diop A, et al. Characterization of the mechanical behaviour parameters of the costo-vertebral joint. Eur Spine J 1998;7:16-23.

[26] Lafon Y, Lafage V, Dubousset J, Skalli W. Intraoperative threedimensional correction during rod rotation technique. Spine 2009;34:512-9.

[27] Lafon Y, Lafage V, Steib JP, et al. In vivo distribution of spinal intervertebral stiffness based on clinical flexibility tests. Spine 2010;35: 186-93.

[28] Pezowicz C, Glowacki M. The mechanical properties of human ribs in young adult. Acta Bioeng Biomech 2012;14:53-60.

[29] Sandoz B, Badina A, Laporte S, et al. Quantitative geometric analysis of rib, costal cartilage and sternum from childhood to teenagehood. Med Biol Eng Comput 2013;51:971-9.

[30] Steib JP, Dumas R, Mitton D, Skalli W. Surgical correction of scoliosis by in situ contouring: a detorsion analysis. Spine 2004;29: 193-9.

[31] Fornasini P. The uncertainty in physical measurements: An introduction to data analysis in the physics laboratory. Springer Science; 2008.

[32] Clin J, Aubin CE, Lalonde N, et al. A new method to include the gravitational forces in a finite element model of the scoliotic spine. Med Biol Eng Comput 2011;49:967-77.

[33] Odermatt D, Mathieu PA, Beausejour M, et al. Electromyography of scoliotic patients treated with a brace. J Orthop Res 2003;21:931-6.

[34] Portier L, Thibault A, Skalli W, et al. Approche d'une modélisation globale, tridimensionnelle par éléments finis, de la colonne vertébrale pour l'étude de la scoliose. Rachis 1993;5:5.

[35] Chazal J, Tanguy A, Bourges M, et al. Biomechanical properties of spinal ligaments and a histological study of the supraspinal ligament in traction. J Biomech 1985;18:167-76. 